\title{
CORRECTION.
}

In the article on "Leakage Prevention by Shielding, Especially in Potentiometer Systems," by Walter P. White, which appeared in the October number of this year, on page 2018 , 7 th line from the bottom of the page, instead of: "arrangement described in connection with Fig. 7 of the previous paper on potentiometers," it should read: "arrangement described in connection with Section $4,(a)$ of the previous paper on potentiometers, page $1875 . "$

\section{THE PARTIAL VAPOR PRESSURES OF TERNARY MIXTURES OF TOLUENE, CARBON TETRACHLORIDE AND ETHYLENE BROMIDE.}

By M. A. Rosanoff, John F. W. Schulze and R. A. DUnphy.

Received August 17, 1914.

The measurements reported in this paper were carried out in connection with a study of fractional distillation with regulated stillheads. In the case of binary mixtures, F. D. Brown ${ }^{1}$ has shown that, if a saturated

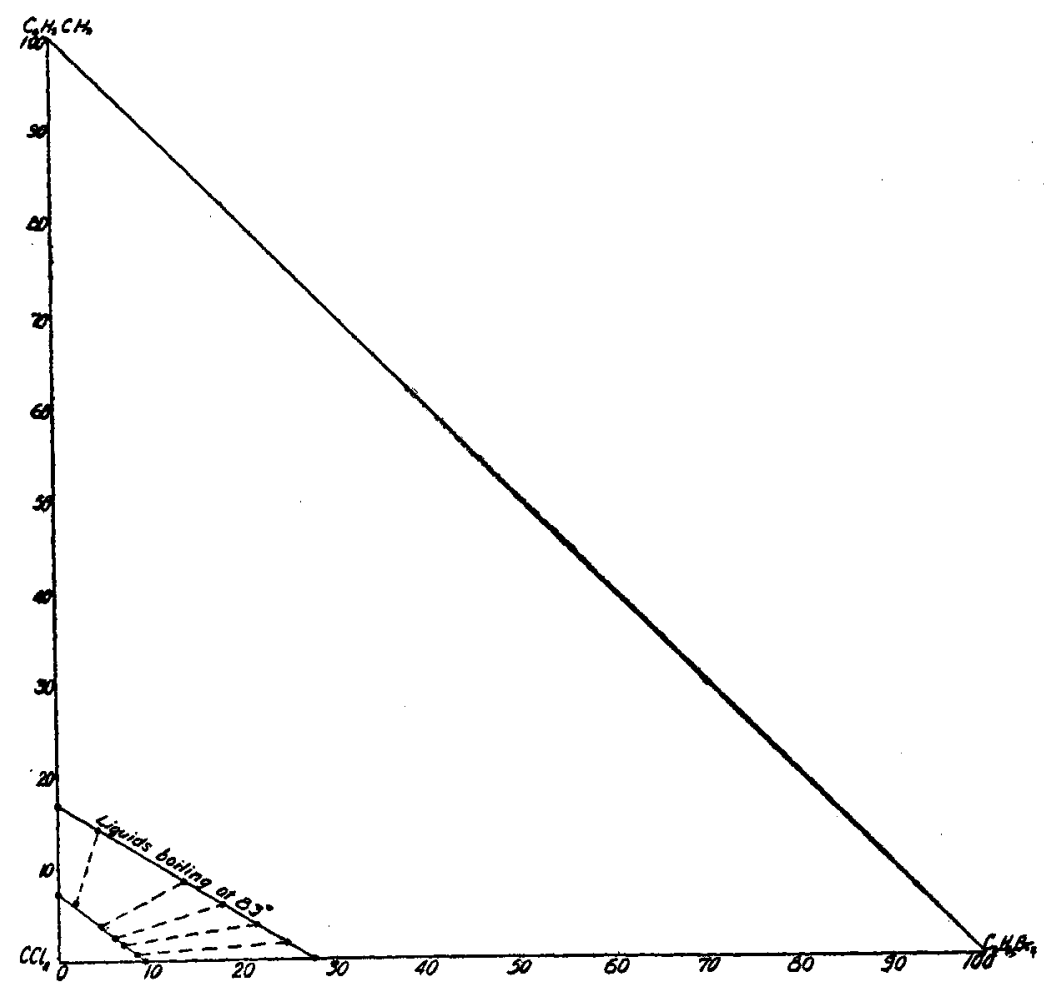

Fig $x$.

1 F. D. Brown, Trans. Chem. Soc., 37, 49 (1880) and especially Ibid., 39, 517 (1881). 